\title{
Fabrication of the Polymer Surface-relief Diffusers by Using the Extrusion Roller Embossing Process
}

\author{
Xiaowei Wang ${ }^{* 1}$, Yongqiang Zhang ${ }^{1}$ \\ ${ }^{\mathbf{1}}$ Mining Machinery Manufacturing Maintenance Branch \\ company \\ ${ }^{1}$ Shenhua Ningxia Coal Industry Group Co. Ltd. \\ ${ }^{1}$ Yinchuan, China \\ 1wxw.1217@163.com
}

\author{
Xiaoxu Wang ${ }^{2}$ \\ ${ }^{2}$ Zhangzheng Middle School \\ ${ }^{2}$ Xingqing District education bureau \\ ${ }^{2}$ Yinchuan, China \\ ${ }^{2}$ wxx_1027@163.com
}

\begin{abstract}
This paper an innovative and effective extrusion roller embossing process, which enables the rapid fabrication of surface-relief polymer diffusers. The metallic roller mould bearing the microstructures is fabricated using the chemical corrosion method. During the extrusion roller embossing process, the extruded polymer sheet is immediately pressed against the surface of the roller mould. Under the proper processing parameters, high-performance polymer diffusers have been successfully fabricated. The shape, uniformity and optical properties of fabricated diffuser have been verified. The experimental results suggest that the extrusion roller embossing process could provide an effective way for continuous fabricating high-performance polymer surface-relief diffusers with the high-performance, low cost and high throughout.
\end{abstract}

Keywords-extrusion roller embossing; fabrication; diffuser; microstructure

\section{INTRODUCTION}

In recent years, LCDs have been widely used in many application, such an LCD TVs, LCD monitors, or etc. The liquid crystals can not emit light, so a back light unit (BLU) is needed to convert the linear and point light source into surface light source. The diffusers, a key optical element in BLU, play a critical role for brightness homogenizing, beam shaping and light scattering. This allows for directed intensity light patterns with high efficiency.

In general, the diffusers can be classified into two types: the particle-diffusing type or the surface-relief type. On the one hand, particle-diffusing diffusers rely on the transparent beads inside the polymer films and sheets to scatter light. The method for fabricating particle-diffusing diffusers, such as extrusion molding [1-2], micro-injection [3], electro-spray method [4] and commercialized coating method, have been reported. However, the distribution of diffusing beads in the diffusers is non-uniform, which affects the performance of diffusing light. On the other hand, surface-relief diffusers rely on the microstructure on the surface of the polymer films or sheets to scatter light. Many methods have been developed to fabricate surface-relief diffusing by replicating microstructures onto the surface of polymer sheet, including Polydimethylsiloxane (PDMS) replica molding [5], photo-fabrication [6], holographic recording method [7], hot embossing [8] and etc. However, most replication methods employ complex processes and require expensive equipment. Among them the hot embossing is a relatively low-cost replication method for fabrication polymer surface-relief diffusers. The embossing step, involving heating and cooling process, is time-consuming batch-wise process, which make the hot embossing an inefficient method for mass production. The goal of this report is to develop an innovation and efficient process for fabricating the polymer surface-relief diffusers.

An innovative and efficient extrusion roller embossing process for directly replicating microstructure onto the polymer films or sheets is reported in this paper. This new process is composed of the single-screw precision extrusion technology and the roller embossing process, which the single-screw precision is used to extrude polymer films and the roller embossing process is used to fabricate microstructures onto the surface of polymer sheets. Therefore, this new craft process not only can fabricate the polymer diffusers with surface-relief function, but also can raise the productivity noticeably. During the extrusion roller embossing process, the extrude sheet is immediately pressed against the surface of roller mold. Polymer diffusers with surface-relief function can be successfully fabricated. The change of temperature in extrusion roller embossing process has been studied. Besides, the uniformity, profiles and optical properties of the fabricated diffusers have been characterized and verified.

\section{EXPERIMENTAL SETUP}

\section{A. Extrusion Roller Embossing System and Process}

The aid of this experiment is to fabricate directly the microstructure on the extrusion polymer sheets by the laboratory-developed extrusion roller embossing system. As shown in Fig.1, the extrusion roller embossing facility has been designed, constructed and used for the fabrication of polymer diffusers in this study. The extrusion embossing facility is consists of polymer sheet extrusion institution and the roller embossing institution. The extrusion embossing facility, which integrates the precision single-screw extruder with the coat-hanger die, is used to fabricate the polymer sheets. Inside the screw extruder are three zones: solids conveying zone, melting zone, metering pumping zone. The final metering zone is the most important section in melt extruder that relies on it to generate pressure sufficient for pumping. The pumping capacity in the metering section can be estimated by solving the equation of motion. Basically, the flow rate is the sum of drag flow and pressure-driven flow. Basically, the flow rate during a Newtonian fluid is sum of drag flow and pressure-driven flow, which can be obtained by the analytical solution. Then the melt is pumped into the die. The thickness of polymer sheets can 
adjust the lip thickness of coat-hanger die. The lip thickness of die for this experiment is $1 \mathrm{~mm}$, which means that the thickness of extruder sheet is $1 \mathrm{~mm}$.

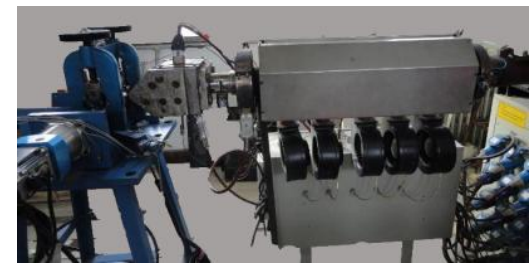

Figure 1. Photograph of extrusion roller embossing system

The gap and the embossing pressure of the roller embossing institution can be controlled by gear wheel institution. The driving roller is driven by a DC motor which has a rotation speed of $1500 \mathrm{rpm}$, and a torque of $2.30 \mathrm{~N} . \mathrm{m}$. The maximum rotation speed of driving roller is 30rpm by using reduction gear box. The roller embossing machine includes driving roller and embossing roller, which the diameter of the roller is $64 \mathrm{~mm}$ and the length is $125 \mathrm{~mm}$.

The specific technological process for the extrusion roller embossing system is described in Fig. 2 as follows. First, the polymer pellets are fed into the extruder to be melted and mixed in the barrel. Second, the polymer melt is extruded out from a coat-hanger die (film-maker). After the polymer sheet is extruded, the hot polymer sheets directly enter into the gap between the driving roller and the embossing roller (microstructure roller). With the proper pressure of the embossing roller, the polymer sheets are squeezed continuously between the driving roller and embossing roller. Thus the microstructures on the embossing roller are replicated onto the polymer sheet. After cooling, the polymer surface-relief sheets are obtained.

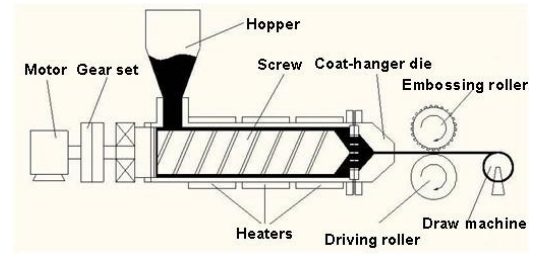

Figure 2. Schematic diagram of extrusion roller embossing system

\section{B. Fabrication of Embossing Roller Mold}

The embossing roller mold produces the microstructures on the polymer sheets surface during extrusion roller embossing process, so it is the key of whole process. There are two type methods for making the embossing roller mold. Firstly, it is surrounded and fixed to the roller for making the embossing roller after manufacture of the uniform thickness and thin micro-structure plat mold. It must be noted how to fix the mold to the roller, in order that the embossing roller is of the very high roundness. Secondly, the embossing roller is directly produced using turning, etching, energy beam and tec. The embossing roller for this experiment is fabricated by coating the slab mold. The microstructures on the steel sheet surface are fabricated using etching, the sheet is coated on the roller closely. The seam is connected with together by argon arc welding or soldering. Finally, the weld joint is polished in order to ensure the roundness of embossing roller. Fig. 3 shows the optical image of the embossing roller. It is measured that the diameter of micro-lens is $175.3 \mu \mathrm{m}$, the depth is $44.0 \mu \mathrm{m}$.

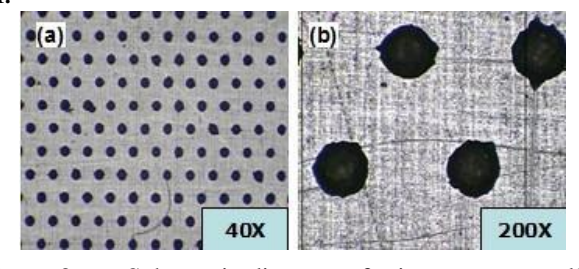

Figure 3. Schematic diagram of microstructure roller

\section{RESUlTS AND DiscUSSION}

A. The Change Trend of Polymer Temperature in the Extrusion Roller Embossing Process

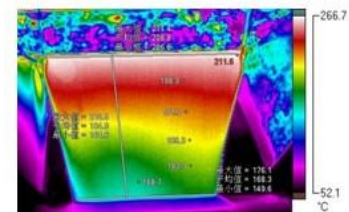

(a)

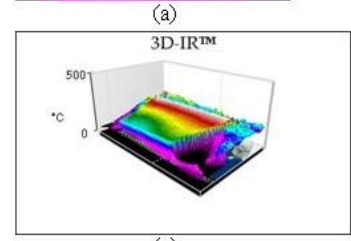

(c)

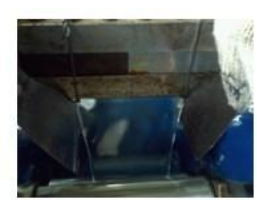

(b)

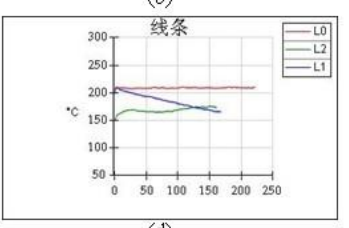

(d)
Figure 4. Temperature distribution of polypropylene sheet before hot embossing. L0: Temperature distribution of the polymer sheet in the die outlet; L1: Temperature distribution of the polymer sheet in the extrusion process; L2: Temperature distribution of polymer sheet in the embossing roller inlet.
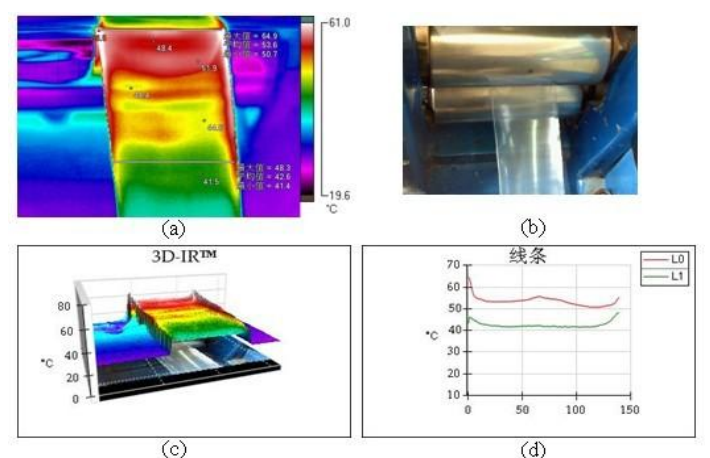

Figure 5. Temperature distribution of polypropylene sheet after hot embossing. L0; Temperature distribution of the polymer sheet in the embossing roller outlet; L1; Temperature distribution of the polymer sheet from the embossing roller $20 \mathrm{~cm}$

In the extrusion roller embossing process, polymer surface temperature is the most important factor to affect the quality of replicating microstructures. Therefore, it is very important to research the change trend of polymer sheets temperature in the extrusion roller embossing process. During this process, a thermal infrared imager (Fluke Ti32, Fluke Thermography Company, USA) was employed to inspect and verify the temperature of polymer sheet in different points. The transparent Polypropylene (PP) (T8042, Yanshan Sinopec Corporation, Beijing) is used to fabricate the polymer surface-relief diffusers. The temperature of four extruder heater sets $175^{\circ} \mathrm{C}, 190^{\circ} \mathrm{C}, 200^{\circ} \mathrm{C}, 205^{\circ} \mathrm{C}$ and the 
coat-hanger die is $205^{\circ} \mathrm{C}$, the rotation speed of embossing roller is $2 \mathrm{rpm}$, and the embossing pressure is $8200 \mathrm{~N}$. Under in this condition, the PP surface-relief diffusers will be fabricated. Fig. 4 shows the temperature distribution, the visible images, the 3D temperature distribution, and the temperature curve of the polypropylene plate before roller embossing. As we can see in the above figures, the average temperature of polymer sheet surface in the embossing roller inlet is $208.8^{\circ} \mathrm{C}$, and the present temperature distribution is very uniform. When the polymer sheets enter into the embossing roller, the average temperature drops to $168.3^{\circ} \mathrm{C}$. In this time, the temperature of the polymer sheets reduces $40^{\circ} \mathrm{C}$ gradually, but the surface temperature of polymer sheet is still near to the melting point (the melting point is $165^{\circ} \mathrm{C}$ ) which the surface of polymer sheets is still in the semi-solidified state. The experimental results show that the transparent Polypropylene (PP) is suitable for extrusion roller embossing experiments. As the same time, the high surface temperature of the PP sheets can reduce the roller pressure. Fig. 5 shows that the average temperature of PP sheets in embossing roller exit is $53.6^{\circ} \mathrm{C}$, and the embossing roller is $49.3^{\circ} \mathrm{C}$. After the extrusion roller embossing process, the surface temperature of polymer sheets drops of $115^{\circ} \mathrm{C}$ suddenly, it is main reason that the cold roller absorbs the large mounts of heat on the polymer sheets.

\section{B. Shape and Uniformity of Fabricated Diffusers}

Fig. 6 shows the optical images of randomly selected are of diffuser fabricated by extrusion roller embossing process under the conditions for $210{ }^{\circ} \mathrm{C}$ of the die temperature, $2 \mathrm{rpm}$ of rotation speed, and $8200 \mathrm{~N}$ of embossing pressure. It is noticed that the microstructures on the embossing roller were successfully replicated onto the extruded PP sheets. At the same time, the microstructure embossed on the PP diffusers was measured. The average height of the microstructures is $173.1 \mu \mathrm{m}$, and the average depth is $42.2 \mu \mathrm{m}$, respectively. The calculated deviations of the average height and the average depth of embossed PP microstructures from the metal embossing roller are $2.2 \mu \mathrm{m}(1.25 \%)$ and $1.8 \mu \mathrm{m}$ $(3.6 \%)$, respectively. The small deviations show that it has a good transcription for fabricating PP diffusers by extrusion roller embossing process.

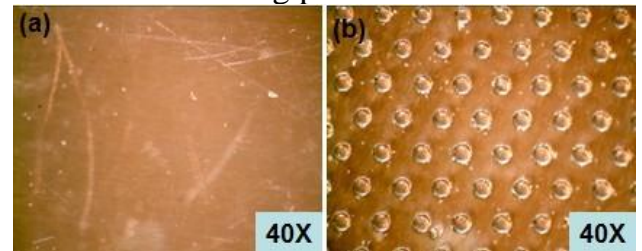

Figure 6. Optical micrograms of the samples by the extrusion roller embossing process. a. pure PP sheet; b. PP sheet with surface microstructures

\section{Optical Properties of the Fabricated Diffusers}

To further inspect and verify the optical properties of the fabricated polymer surface-relief diffusers, an automatic haze meter (WGFS, Shanghai Precision Scientific Instrument Company) is employed, which follows the ASTM D1003. For ASTMD1003, it is a standard test method for haze and luminous transmittance of polymer diffusers. The automatic haze meter is composed of an integrated sphere, a condenser, a lens, a photo detector and a light source, which the transmittance $\left(T_{t}\right)$ and haze of diffusers can be measured. The $T_{t}$ and haze of the fabricated PP diffuser with microstructures are $82.5 \%$ and $34.6 \%$ respectively, which show the good diffusing performance. Tab.1 compares the optical properties of the even PP sheet and PP diffusers with microstructures. The result shows that the $T t$ will decline and the haze will increase which there are microstructure on the polymer diffusers surface.

TABLE I. OPTICAL PERFORMANCE OF THE FABRICATION DIFFUSERS

\begin{tabular}{ccc}
\hline & $T_{t}(\%)$ & Haze $(\%)$ \\
\hline Pure PP sheet & 88.1 & 26.0 \\
PP diffuser with surface & 82.5 & 34.6 \\
microstructures & & \\
\hline
\end{tabular}

Furthermore, to inspect the diffusion PP capacity of the polymer plates, an optical system, which is consisted of a $543 \mathrm{~nm}$ wavelength laser light source, an object holder and a camera, is used. Fig. 7 shows the images observed through the flat PP sheets and the PP sheets with microstructures. As can be observed, the PP sheets with microstructures displays better diffusing efficiency than the flat PP sheets. The result testifies that the fabricated polymer diffusers with surface-relief function can scatter the light uniformity and diffuse the light effectively.
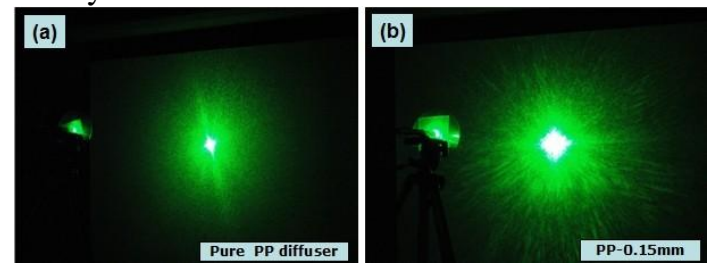

Figure 7. The images of a laser light source observed behind through the fabrication diffuser

Finally, it should be noticed that the smaller microstructure which can be successfully fabricated by the current extrusion roller embossing process is limited by the availability of the embossing roller mold. This process can be used to fabricate the polymer diffusers with the smaller size microstructure as long as the metallic embossing roller mold is acquired. On the other hand, this method is the continuous process, so it can be achieved the mass production for fabricating the polymer diffusers with microstructures. This would provide significant advantage is terms of reduced fabrication cost and improve product quality.

\section{CONCLUSIONS}

This paper discussed an innovative and effective embossing method for the rapid fabrication of polymer surface-relief diffusers. In this paper, the extrusion roller embossing system which combines precision single-screw extrusion and roller micro-embossing has been set up to replicate the microstructure. Under the proper processing parameters, the surface features on embossing roller can be replicated onto extruded polymer sheets. The polymer diffusers with microstructures have been successfully fabricated. The profiles, uniformity and optical properties of fabricated polymer surface-relief diffuser have been 
characterized and verified. Compared with two types polymer diffusers, the fabricated surface-relief diffusers can scatter light uniformity and diffuses light effectively. In the end, the experimental results suggest that the extrusion roller embossing process could provide an innovative and effective way for fabricating the polymer surface-relief diffusers with high-performance, low cost, and high throughput.

\section{REFERENCES}

[1] G. H. Kim, "A PMMA composite as an optical diffuser in a liquid crystal display backlight unit(BLU)," Eur. Ploym., 2005, vol. 41, pp. 1729-1737;

[2] G. H. Kim, W. J. Kim, S. M. Kim, and et al, "Analysis of thermo-physical and optical properties of a diffuser using PET/PC/PBT copolymer in LCD backlight units," Displays, 2005, vol. 26, pp. 37-43;
[3] E. Turcott, and K. T. Nguyen, "Microstructure development during the injection molding of PET/LCP blend," Ploym. Engin. Sci., 2001, vol. 41(4), pp. 603-617;

[4] G. H. Kim and J. H. Park, "A PMMA optical diffuser fabricated using an electro-spray method," Appl. Phys. 2007, Vol. A 86, pp.347-351;

[5] T. K. Shin, C. F. Chen, J. R. Ho, and et al, "Fabrication of PDMS microlens and diffuser using replica molding," Microelectron. Eng., 2006, vol. 83, pp. 2499-2503;

[6] S. I. Kim, Y. S. Choi, Y. N. Ham, and et al, "Microlens array diffuser for a light-emiting diode backlight system," Opt. Lett. vol. 31, pp. 3016-3018;

[7] D. Sakai, K. Harada, S. I. Kamemaru, and et al, "Holographic diffuser by use of a silver halide sensitized gelatin process," Appl. Opt. vol. 42, pp. 2482-2491;

[8] M. Parikka, T. Kaikuranta, P. Laakkonen, and et al, "Deterministic diffractive diffusers for displays," Appl. Opt., 2001, vol. 40, pp. 2239-2246. 